\title{
Inhaled corticosteroids in COPD: the clinical evidence
}

\author{
Pierre Ernst ${ }^{1,2}$, Nathalie Saad ${ }^{1}$ and Samy Suissa ${ }^{2,3}$ \\ Affiliations: ${ }^{1}$ Dept of Medicine, Pulmonary Division, Jewish General Hospital, Montreal, Canada. ${ }^{2}$ Centre for \\ Clinical Epidemiology, Lady Davis Research Institute, Jewish General Hospital, Montreal, Canada. ${ }^{3}$ Dept of \\ Epidemiology and Biostatistics, McGill University, Montréal, Canada.
}

Correspondence: Pierre Ernst, Centre for Clinical Epidemiology, Lady Davis Research Institute, Jewish General Hospital, 3755 Cote Ste-Catherine, Montreal, Quebec, H3T 1E2, Canada. E-mail: pierre.ernstamcgill.ca

ABSTRACT In this article, we focus on the scientific evidence from randomised trials supporting treatment with inhaled corticosteroids (ICS) in chronic obstructive pulmonary disease (COPD), including treatment with combinations of long-acting $\beta$-agonist (LABA) bronchodilators and ICS. Our emphasis is on the methodological strengths and limitations that guide the conclusions that may be drawn.

The evidence of benefit of ICS and, therefore, of the LABA/ICS combinations in COPD is limited by major methodological problems. From the data reviewed herein, we conclude that there is no survival benefit independent of the effect of long-acting bronchodilation and no effect on FEV1 decline, and that the possible benefit on reducing severe exacerbations is unclear. Our interpretation of the data is that there are substantial adverse effects from the use of ICS in patients with COPD, most notably severe pneumonia resulting in excess deaths.

Currently, the most reliable predictor of response to ICS in COPD is the presence of eosinophilic inflammation in the sputum. There is an urgent need for better markers of benefit and risk that can be tested in randomised trials for use in routine specialist practice. Given the overall safety and effectiveness of long-acting bronchodilators in subjects without an asthma component to their COPD, we believe use of such agents without an associated ICS should be favoured.

@ERSpublications

The benefits of ICS in COPD are limited. Better tools are needed to identify which patients might benefit. http://ow.ly/EwuhS 


\section{Introduction}

Chronic obstructive pulmonary disease (COPD) has become a major worldwide killer [1] as well as causing very substantial morbidity and costs [2-4]. In most places in the world, COPD results from cigarette smoking and, therefore, the prevention of smoking [5] and the treatment of nicotine addiction should be the first priority in tackling COPD. However, far greater amounts of money are spent on drug therapy for COPD than on smoking cessation. In this narrative review, we will focus on the scientific evidence supporting treatment with inhaled corticosteroids (ICS) in COPD, including treatment with combinations of long acting $\beta$-agonist bronchodilators (LABA) and ICS. This scientific evidence includes observational studies that have generally shown very favourable outcomes of ICS and LABA/ICS on major COPD outcomes such as hospitalisation and mortality [6-9]. We have argued that these studies are affected by time-related biases that exaggerate the benefit of ICS $[10,11]$. In this article, we will mostly restrict our review to randomised trials of ICS and LABA/ICS. Our emphasis will be on the methodological strengths and limitations that guide the conclusions that may be drawn as to the efficacy and safety of ICS and LABA/ICS in the treatment of COPD (table 1).

\section{Early randomised clinical trials of ICS alone}

The early trials of ICS therapy in COPD were carried out in patients with mild disease, with a baseline forced expiratory volume in $1 \mathrm{~s}$ (FEV1) near $80 \%$ predicted $[12,13]$. Neither of these studies was able to show a benefit on decline in FEV1 and in the study by VeSTBO et al. [13], the exacerbation rate was similar in the ICS and placebo groups. The Lung Health Study included patients with a lower FEV 1 (mean 56\% predicted) and found no difference in decline in lung function in those randomised to the ICS triamcinolone (fig. 1), while the ICS-treated group reported fewer visits to a physician for respiratory illness [14]. Subsequent trials included patients with more severe airflow obstruction (mean FEV $1 \leqslant 50 \%$ predicted) and reported decreased rates of exacerbation or prolonged time to first exacerbation [15-18] with ICS. A meta-analysis of these studies concluded that there was an overall $30 \%$ reduction in acute exacerbations of COPD (AECOPD) with ICS [19]. We have criticised the analysis of exacerbations in these early studies, however [20,21]. Principally, some of these studies did not weight the rate of exacerbations according to differences in duration of follow-up between patients, which will exaggerate the influence of those subjects dropping out early. This is especially problematic in COPD studies with long durations of follow-up where dropout rates have been in the range of $20-50 \%$ and observed to occur early after randomisation, more so in the placebo group. Authors further assumed that patients were homogeneous as to their rates of AECOPD rather than accounting for the fact that some patients may have many exacerbations and many patients none [22]. This assumption underestimates the variation in the data and will provide falsely low p-values and narrow confidence intervals [20, 21]. Therefore, these early studies suggesting a benefit of ICS in reducing exacerbations among COPD patients with severe airways obstruction are likely to have overestimated the potential benefit. More recent studies of ICS/LABA $[23,24]$ have used weighting of exacerbations according to total person-time of follow-up. In addition, the more current studies now consider the wide between-patient heterogeneity in exacerbation rates using the appropriate statistical techniques. Whether using an overdispersion parameter in the Poisson regression analysis of the rates [21] or the practically equivalent approach of a negative binomial analysis [24-26], this important variability in the analysis of COPD trials involving exacerbations is now well recognised [27]. While ICS probably do reduce moderate exacerbations of COPD [28], ICS alone are not superior to LABA and are less safe according to a Cochrane meta-analysis by SPENCER et al. [29] that pooled randomised controlled trial (RCT) data comparing the benefits of ICS to LABA, each used singly.

TABLE 1 Limitations of the evidence suggesting that inhaled corticosteroids (ICS) and long-acting $\beta$-agonists (LABA)/ICS decrease exacerbations of chronic obstructive pulmonary disease

Most trials do not follow patients for the outcome of exacerbations after drug discontinuation (not ITT) Loss to follow-up frequent and related to both treatment received and outcome, causing bias Exacerbations variably defined

Differences between groups possibly exaggerated by withdrawal of ICS in placebo and LABA groups Incorrect calculation of NNT

Incorrect adjustment for heterogeneity of number of exacerbations between patients in early studies

ITT: intention to treat; NNT: number needed to treat. 
FIGURE 1 Decline in postbronchodilator forced expiratory volume in $1 \mathrm{~s}$ among subjects randomised to triamcinolone or placebo in the Lung Health Study. Reproduced from [14] with permission from the publisher.

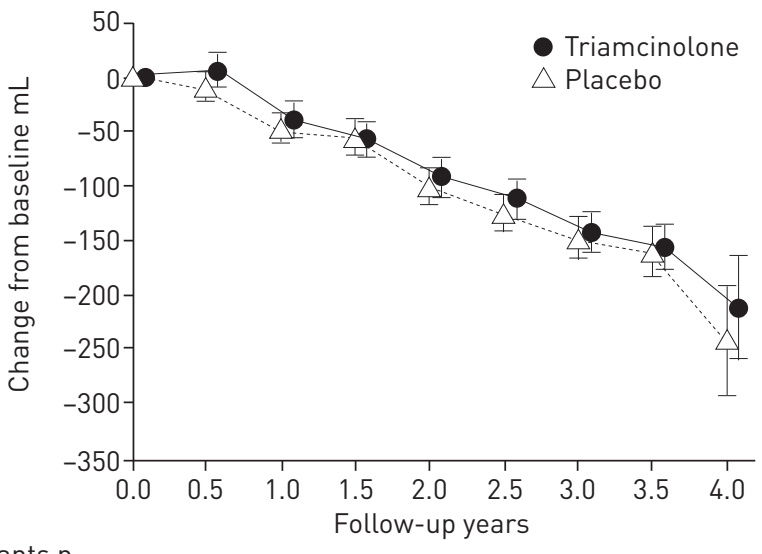

Participants $n$

Triamcinolone $\begin{array}{llllllllll}556 & 511 & 513 & 490 & 499 & 485 & 479 & 388 & 81\end{array}$

$\begin{array}{llllllllll}\text { Placebo } & 556 & 506 & 503 & 489 & 501 & 484 & 488 & 406 & 77\end{array}$

\section{RCTs of LABA/ICS combinations and their methodological limitations}

Towards a Revolution in COPD Health (TORCH) [25] was a landmark study in many ways. It recruited a sufficient number of patients followed for 3 years to examine mortality in relation to treatment of COPD with ICS and the LABA/ICS combination. For the outcome of all-cause mortality, the study provided a true intention-to-treat (ITT) analysis, having followed all patients to the end of the 3-year study period for the death end-point, regardless of whether they had continued the study medications. The study conclusively showed that ICS do not reduce mortality in patients with COPD. There was a trend toward improved survival with the LABA/ICS compared with placebo, but this did not achieve statistical significance. There were four treatment groups in TORCH: placebo, fluticasone, salmeterol, and salmeterol and fluticasone combined in a single inhaler. This factorial design allows one to derive information on the individual effects of salmeterol and fluticasone, not only from those subjects randomised to the individual agent but also from those receiving the combination. Such a factorial analysis, performed post hoc, found a statistically significant and important 19\% (95\% CI 6-30\%) survival advantage with the use of the LABA salmeterol but none whatsoever from the fluticasone component [30].

Unfortunately, a true ITT analysis was not possible for symptoms, exacerbations, FEV1 decline and quality of life because follow-up of these outcomes was not obtained after the subjects discontinued the study medications. For these outcomes, TORCH becomes a prospective cohort study where bias in the estimate of the effect will result if the likelihood of dropping out differs according to the treatment received at randomisation and is related to the outcome under study. For example, a subject who feels unwell in relation to early signs of exacerbation may withdraw from the study and the subsequent severe exacerbation would not be counted. This is well illustrated by the $\sim 25 \%$ rate of severe exacerbation in COPD subjects $\geqslant 31$ days after discontinuing randomised therapy [31]. Such a bias would probably not be significant if the rate of discontinuation was low. In TORCH, however, $35 \%$ of subjects randomised to LABA/ICS and $45 \%$ of those randomised to the placebo group did not complete the 3-year follow-up, including the $21 \%$ who dropped out in the first year. Furthermore, loss to follow-up was not random: patients who dropped out were older, had a lower FEV1 and greater exacerbation history [32].

It has been argued that the higher dropout rate in the placebo group and the availability of the study medications on the market will have led to an underestimation of the treatment benefit [31,32]. This is not necessarily so. The one study that did follow patients to the end of the study period was unable to show a reduction of exacerbations with the addition of LABA/ICS to tiotropium [33]. Using data from this same study, AARON et al. [20] were able to demonstrate an important exaggeration of the reduction in risk of exacerbation by simulating dropping patients who stopped the study medications. Furthermore, many subjects recruited to TORCH were receiving the treatments under study at the time of recruitment and were required to stop these prior to randomisation. This may be only a minor problem for addressing benefits of long-acting bronchodilators, as subjects were allowed to use short-acting bronchodilators. For ICS, however, one might speculate that subjects who were previously on ICS would tend to be those who had experienced the most benefit (as they might be expected to be more compliant to this therapy) and, therefore, the salmeterol and placebo group experience may reflect, at least in part, the withdrawal of ICS. This is supported by subsequent analyses of TORCH that showed that having ICS withdrawn at recruitment was a predictor of withdrawal from the study [32]. Again, using information gathered during the Canadian 
Optimal Therapy of COPD Trial, we were able to show that the reduction in exacerbations with the ICS component of the LABA/ICS arm was limited to subjects who were already receiving ICS at the time of study initiation and were possibly more likely to have experienced benefit [34]. A subsequent re-analysis of TORCH did not find a difference in exacerbation rates according to prior ICS use, however [35].

Cardiovascular disease is common in patients with COPD and contributes substantially to mortality [3638]. Observational studies have suggested possible benefits of ICS on cardiovascular outcomes [39, 40]. A post hoc analysis of cardiovascular events in the TORCH study suggested that the LABA/ICS combination may be cardioprotective [41]. SUMMIT (the Study to Understand Mortality and Morbidity in COPD) will examine the potential benefits of the new LABA/ICS combination, vilanterol/fluticasone furoate, on survival among patients with moderate COPD and cardiovascular comorbidity [42]. Unfortunately, patients already on a LABA/ICS combination or its components will be recruited and their medications stopped. Therefore, once again, the observed effects will be those resulting from a combination of direct treatment effects and withdrawal of prior treatments, making the results of that trial difficult to interpret [43].

The most clinically pertinent comparison to delineate the role of ICS in COPD is the contrast of LABA/ ICS with bronchodilators alone. A recent meta-analysis of studies comparing LABA/ICS to LABA alone questioned the superiority of the combination in reducing exacerbations, noting that no reduction in COPD hospitalisations was seen and voiced concerns as to the analysis and the availability of data [44]. Specifically, attrition rates were high and the analysis of exacerbations remains problematic [20]. A recent study of a new LABA/ICS combination at various doses versus the LABA alone also did not find a benefit of the LABA/ICS combination versus the LABA alone on severe exacerbations [24, 45].

In several articles reporting a reduction in AECOPD with a LABA/ICS combination, authors have provided a number needed to treat (NNT) that appears very favourable [23-25]. The NNT is based on the absolute risk difference (one divided by the absolute difference in the proportion of subjects with the outcome event). This proportion is measured by the cumulative incidence of the event over the treatment period, using statistical tools such as the Kaplan-Meier curve, which applies both for a dichotomous outcome such as death and, if the outcome can occur more than once, the time to the first occurrence (e.g. the first AECOPD). A study by KARDOs et al. [23] reported a NNT of 3 subjects to prevent one AECOPD, while the number reported in TORCH was 4 and was 3.3 in a recent study of a new LABA/ICS [24, 25]. This was obtained by calculating an absolute risk reduction based not on the difference in the proportion of subjects with an AECOPD, but rather on differences in rates of AECOPD in two groups, and termed an "event-based" NNT [46]. This use of the rate rather than the cumulative incidence is inappropriate and illogical, as demonstrated by AARON and FERGUSON [47]. Suissa has described an alternative method for the correct calculation of the number to treat in this context when the Kaplan-Meier curve of the cumulative incidence is not available using a trial of fluticasone-salmeterol versus salmeterol alone [48, 49]. Suissa found an event-based NNT of 14 rather than the NNT of 2 reported in the paper.

The seminal work of Fletcher and Peto [50] demonstrated the progressive and excessive decline in FEV1 to be a major feature of COPD. Therefore, reducing FEV1 decline has been a goal of many large COPD treatment trials. As mentioned previously, early trials of ICS in patients with mild COPD did not show a slowing of the decline in FEV1 [12, 13]. Two meta-analyses including studies with a broader range of patients came to opposite conclusions based on an aggregate analysis of mostly the same studies [51, 52]. A Cochrane review in 2012 [28] concluded that ICS in COPD did not modify FEV1 decline. The TORCH study examined the effect of an LABA/ICS combination, as well as the individual components, on FEV1 decline [53]. The authors reported that all treatment groups showed significantly less decline in FEV1 than the placebo group and further stated that the difference in decline compared with placebo was minimised due to the greater dropout rate in the placebo group. This is a misconception, as previously demonstrated by one of us [54]. In the analysis of FEV1 decline in the TORCH data, nearly $18 \%$ of patients in the placebo group did not have an FEV1 measurement at 6 months, the time from which decline was measured [53]. There were also fewer patients in the placebo group who had the full complement of follow-up measurements. These missing results did not occur at random and exaggerate differences in FEV1 decline between the placebo and treatment groups through the statistical phenomenon of regression to the mean [54]. This is a further consequence of not following patients until the end of the study period and particularly after treatment discontinuation, thus not permitting a true ITT analysis.

\section{Safety of ICS and LABA/ICS in COPD}

COPD patients are at greater risk of pneumonia [55] and are at increased risk of dying when contracting pneumonia [56]. The TORCH study was the first to report an excess of pneumonia among COPD patients receiving ICS either alone or in combination with a LABA. The significance of this finding was not immediately accepted because pneumonia was not a pre-specified outcome and chest-radiographic confirmation of the diagnosis was not required [57]. Our group carried out a large prospective cohort 
study in a healthcare administrative database and found an overall 70\% (rate ratio (RR) 1.70, 95\% CI 1.63 1.77) increase in pneumonia requiring hospitalisation, with the greatest risk (RR 2.25, 95\% CI 2.07-2.44) seen in patients dispensed a daily fluticasone-equivalent dose $\geqslant 1000 \mu \mathrm{g}$ [58], the dose used in TORCH and other large COPD trials $[25,33,59]$. Subsequent meta-analyses of randomised trials again confirmed the excess pneumonia risk $[60,61]$. In TORCH, the risk of pneumonia was greatest in patients with an FEV $1<50 \%$ predicted and those with a prior COPD exacerbation [57], exactly the group where a LABA/ ICS combination is recommended. An excess of pneumonia was also observed in the Investigating New Standards for Prophylaxis in Reduction of Exacerbations (INSPIRE) study comparing salmeterol/ fluticasone to tiotropium [59]. The excess was observed for pneumonias associated with a current or recent exacerbation [62], which appears paradoxical, given the reported reduction in exacerbations with LABA/ICS combinations. A recent large Canadian observational study did not find an excess of pneumonia in subjects initiating treatment with a LABA/ICS combination compared with a LABA alone [63]. The study design used an ITT approach where ICS use was measured only at cohort entry. With pneumonias possibly occurring up to 5 years later, ICS exposure needed to be updated over time, but was not. Patients classified as users of ICS at cohort entry were exposed to ICS for only $47 \%$ of the days in the first year and 34\% subsequently, while patients classified as nonusers of ICS were actually exposed to ICS for $6 \%$ of the days in the first year, increasing to $23 \%$ by year 5 . Such misclassification of exposure will necessarily attenuate high risks towards the null.

In both the TORCH and INSPIRE studies, there were a relatively small number of pneumonias compared with COPD exacerbations. Using the relative frequencies of events to examine drug effects can be misleading; the results of these studies have been misinterpreted, as demonstrating that a reduction in frequent exacerbations due to the LABA/ICS combination must be more important than an excess of infrequent pneumonias. A way of dealing with these issues is to use comparative effect measures such as the NNT. One of us has shown that the NNT for pneumonias and that for a reduction in COPD exacerbations are quite similar [49]. For example, in the TORCH study, 44 subjects must be treated for 3 years to prevent one patient from having an exacerbation while 16 subjects treated over the same time period will result in one excess case of pneumonia [49]. The excess in pneumonia with the LABA/ICS combination has also been observed with lower doses of the fluticasone component of the LABA/ICS combination $[26,48]$.

Surprisingly, a meta-analysis of randomised trials of budesonide in COPD, either singly or as part of a LABA/ICS combination, did not find an excess risk of pneumonia [64]. Two observational studies also found a lower risk of severe pneumonia with budesonide compared with fluticasone $[65,66]$. There is the possibility, however, that in both jurisdictions in which these studies were carried out, use of the formoterol/budesonide combination may have been a marker of asthma where ICS are not associated with an excess in pneumonia [67]. While the authors of both these studies attempted to limit their analyses to patients with COPD, this may not have been entirely successful. However, a recent study of a new LABA/ ICS combination containing fluticasone furoate found an excess of eight pneumonia deaths, seven in the group receiving the higher-than-recommended dose of this agent, suggesting that fluticasone itself may be particularly troublesome [24]. However, a recent meta-analysis did not exonerate budesonide [68].

Once hospitalised, COPD patients with pneumonia who were receiving ICS are at no greater risk of mortality subsequently $[58,69,70]$. This has been misinterpreted as an absence of an excess in pneumonia deaths among COPD patients on ICS $[57,71]$. Since a greater number of COPD patients receiving ICS are hospitalised for severe pneumonia, more will die from pneumonia even if the case fatality rate is the same once hospitalised. This is emphasised in our results in a large database study of nearly 24000 pneumonias in which patients receiving high doses of ICS equivalent to $\geqslant 1000 \mu \mathrm{g}$ fluticasone propionate had a $70 \%$ greater risk of pneumonia hospitalisation resulting in death within 30 days [58] as well as the recent study of vilanterol/fluticasone furoate where eight deaths from pneumonia occurred in those receiving fluticasone furoate [24].

Pneumonia is the most troublesome adverse effect of ICS in patients with COPD given the size of the relative increase in risk, the frequency of the event and the associated excess mortality. Current use of ICS is also associated with an increase in the risk of active tuberculosis in a low-prevalence setting (RR 1.33, 95\% CI 1.04-1.71), although there is no added risk in patients who already experience an increase in risk from having received oral corticosteroids in the prior year [72]. A similar increase in the risk of tuberculosis was observed in an area with higher prevalence (RR 1.20, 95\% CI 1.08-1.34), again limited to subjects without concomitant use of oral corticosteroids [73]. COPD is also a risk factor for infection with nontuberculous mycobacteria and there is a further dose-related increased risk with ICS [74]. Interestingly, as was the case with pneumonia, the risk appeared to be greater for fluticasone than for budesonide [74]. In a recent study, we did not find an increase in the risk of herpes zoster infections with ICS [75]. 
Corticosteroids affect bone metabolism and increase the risk of osteoporosis [76]. Airflow obstruction, especially if severe, is a further risk for osteoporosis [77]. ICS use is associated with a small additional increase in risk of fractures and the risk increases by approximately 6-12\% at high daily doses of ICS [78-81].

ICS have been shown to have adverse metabolic effects. Early database studies did not identify an increased risk of diabetes in users of ICS $[82,83]$. These studies examined a period of time when the predominant ICS was low-dose beclomethasone. The incidence of diabetes in patients with COPD is insufficiently common for an increase in risk to be picked up in the large COPD trials. A recent meta-analysis of trials of budesonide in both asthma and COPD did not find an excess of diabetes reported as an adverse outcome [84]. However, an increase in blood glucose has been described among diabetic patients receiving ICS [85]. Furthermore, in a crossover study, inhaled fluticasone was shown to increase glycosylated haemoglobin [86]. Recently, in a large database study including patients with both asthma and COPD, we found a 34\% relative increase in the risk of new-onset diabetes (RR 1.34, 95\% CI 1.29-1.39) with current use of ICS, with a higher risk with daily doses equivalent to fluticasone $\geqslant 1000 \mu \mathrm{g}$ (RR 1.64, 95\% CI 1.52-1.76) [87]. There was also a 34\% increase in the risk of progressing to insulin dependence among diabetics treated with oral hypoglycaemic agents [87].

Concerns regarding the occurrence of adrenal insufficiency with ICS were first raised in children, particularly in relation to fluticasone [88-90], as well as in in HIV patients treated with ritonavir which severely affects the metabolism of ICS [91, 92]. Fluticasone may be associated with greater adrenal suppression than budesonide [93]. Mortimer et al. [94] carried out a nested case-control analysis of a cohort of patients followed by general practitioners in the UK and found a small increase in the risk of adrenal insufficiency that was largely explained by a history of use of oral corticosteroids. There was a suggestion of an independent risk with higher doses of ICS and for fluticasone. In a larger study in the Quebec health administrative databases, we again found a large excess risk of adrenal insufficiency related to the cumulative dose of oral corticosteroids, but again a suggestion of a significant independent risk with daily doses of ICS equivalent to fluticasone $\geqslant 1000 \mu \mathrm{g}$ (RR 1.84, 95\% CI 1.16-2.90) [95]. Interestingly, the risk of adrenal insufficiency with ICS was more pronounced in patients with COPD than in patients with asthma [95]. Newer ICS have contrasting effects on adrenal function, with ciclesonide being less suppressive than fluticasone [96], while mometasone and fluticasone appear equivalent [97].

CUMming et al. [98] demonstrated the association between reported use of ICS assessed by questionnaire and the risk of cataracts detected by screening. The need for cataract extraction in the elderly was subsequently linked to prolonged use of ICS ( $\geqslant 3$ years or more) (odds ratio 3.06, 95\% CI 1.53-6.13) in a health administrative database, with a more pronounced risk at daily doses of budesonide or beclomethasone of $>1 \mathrm{mg}$ [99]. A lower risk was found in a general practice prescription database with the risk restricted to those $>40$ years of age [100]. The risk may have been attenuated, however, as exposure to ICS was based on prescriptions rather than on drugs dispensed to patients. We were able to demonstrate an excess of cataracts, including severe cataracts requiring extraction, even at relatively low doses of ICS equivalent to daily doses of beclomethasone $\leqslant 500 \mu \mathrm{g}[101]$.

While oral corticosteroids increase intraocular pressure and the risk of a diagnosis of glaucoma [102], it is far less clear whether ICS actually increase the risk of open-angle glaucoma requiring treatment. In an administrative database study, GARBE et al. [103] reported no overall increase in risk of glaucoma or increased intraocular pressure with current use of ICS, but a small increase in risk at higher doses used for $\geqslant 3$ months. However, treatment for ocular hypertension was only required in approximately half of the cases. In a subsequent study, limited to cases of open-angle glaucoma requiring treatment, we did not find an increase in risk with current use of ICS, even at higher doses [104].

\section{COPD phenotypes or how to predict which patients benefit from ICS}

Personalised medicine has not come to COPD. Part of the problem lies in the difficulty in distinguishing asthma from COPD in patients with persistent airflow limitation. Guidelines have recognised that COPD and asthma may co-exist $[105,106]$ if patients with asthma smoke and airway hyperresponsiveness has been shown to predict decline in lung function over time in smokers with early COPD [107]. To muddy the waters further, the presence of fixed airways obstruction is not uncommon among nonsmokers [108, 109]. A proportion of these cases are probably untreated asthma, the result of airway remodelling in chronic asthma despite treatment or of severe childhood asthma $[110,111]$. In the recent BOLD (Burden of Obstructive Lung Disease) initiative [112], the occurrence of post-bronchodilator airflow limitation found during screening of population-based samples has been termed COPD, regardless of potential aetiological factors such as smoking, asthma or childhood respiratory disease. As has been pointed out, such an approach, if adopted clinically, is unlikely to lead to the correct therapeutic decision for many patients [113] but, rather, has led to widespread confusion [114]. 
The recent Global Initiative for Asthma (GINA) guideline includes a new chapter on the asthma-COPD overlap syndrome (ACOS) developed in conjunction with the GOLD (Global Initiative for Chronic Obstructive Lung Disease) guideline group. It provides suggestions of clinical characteristics that might allow clinicians to identify an asthma component in patients labelled as having COPD [115]. Therapeutic responses in these patients have never really been studied, however, as asthma is an exclusion criterion in most therapeutic trials of COPD, while COPD is an exclusion criterion in trials of asthma. Nevertheless, it is proposed that if features of both asthma and COPD (see Box 5-4 in the GINA report [115]) are present, the term ACOS may be applied and treatment for asthma initiated. This approach has not been validated and is unlikely to be useful in differentiating patients with a significant degree of persistent airway obstruction and daily symptoms, as both these characteristics are considered features of COPD. Identifying different clinical phenotypes for these patients is the key to providing individualised treatment that maximises benefit and reduces harm [116]. While current guidelines identify patients with frequent exacerbations as a clinical phenotype, such patients may rather be farther along in the natural history of the disease [117]. More importantly, while studies of LABA/ICS combinations aimed primarily at reducing exacerbations have recruited patients with prior exacerbations $[23,24,26]$, this does not provide evidence that such patients benefit more from ICS.

The ACOS phenotype appears to provide the most confidence as to the benefit of including an ICS in the treatment regimen. A recent, large observational study reported a survival advantage among patients with COPD starting LABA/ICS versus LABA alone. This survival benefit was observed in those patients with a concomitant diagnosis of asthma but not in those without [63]. Various clinical characteristics might be used to better identify such patients. GINA has proposed that the early onset of airway disease, including a history of childhood asthma as well as a history of atopy, is suggestive of ACOS in patients with persistent airway obstruction. Again according to GINA, laboratory features that point to an asthma component are a normal diffusing capacity and a large bronchodilator response ( $\geqslant 12 \%$ and $400 \mathrm{~mL})$ [115]. Prior claims that bronchodilator response is not pertinent in the differential diagnosis of airflow obstruction are based on several arguments. First, bronchodilator response is not a stable feature in COPD [118], as is also the case with asthma. This does not lessen the fact that large bronchodilator responses $(\geqslant 12 \%$ and $400 \mathrm{~mL})$ are common in asthma, especially if insufficiently treated, and are uncommon in COPD [115, 118, 119]. A study by CALVERLEY et al. [119], which is frequently quoted to argue against the utility of bronchodilator response as a prognostic factor or predictor of treatment response, is based on an analysis of the ISOLDE (Inhaled Steroids in Obstructive Lung Disease in Europe) study in which the mean bronchodilator response to salbutamol was $\sim 10 \%$ or $130 \mathrm{~mL}$. This study had insufficient power to conclude as to the usefulness of larger bronchodilator responses. Similarly, in the ECLIPSE (Evaluation of COPD Longitudinally to Identify Predictive Surrogate Endpoints) study, while $24 \%$ of patients with a diagnosis of COPD met the American Thoracic Society/European Respiratory Society reversibility criteria of an increase in $\mathrm{FEV} 1$ of $\geqslant 12 \%$ and $200 \mathrm{~mL}$, only $5 \%$ of patients met the reversibility criteria using a minimum volume increase of $400 \mathrm{~mL}$. Therefore, the lack of prognostic and diagnostic significance of small responses to bronchodilator cannot be applied to larger responses. In the general population-based CanCOLD (Canadian Cohort of Obstructive Lung Disease) study, bronchodilator responsiveness was strongly associated with a physician diagnosis of asthma (table 2) [120].

Among patients with similar degrees of fixed airflow obstruction, the presence of sputum eosinophilia will distinguish those with asthma from those with COPD better than bronchodilator response or diffusing capacity [121]. In this study, however, the majority of the patients with asthma were nonsmokers. Sputum eosinophilia is a good predictor of response to corticosteroids in asthma and there is a suggestion that ICS response is limited to those with sputum eosinophilia [122, 123]. Sputum eosinophilia also seems to be common in smokers labelled as having COPD [124]. Several studies suggest that sputum eosinophilia in COPD patients also predicts response to corticosteroids [125, 126]. BRIGHTLING et al. [127] carried out a placebo-controlled crossover trial of the ICS mometasone, $800 \mu \mathrm{g}$ daily for 6 weeks in patients with typical COPD (smokers, no response to bronchodilators on two occasions, no history of asthma and no exacerbation on withdrawal of prior ICS) and found that only subjects in the highest tertile of sputum eosinophilia improved their post-bronchodilator FEV1 (fig. 2). However, sputum eosinophilia was not significantly reduced, as opposed to the reduction seen in their prior study using oral corticosteroids [125], suggesting that the dose and duration of ICS therapy may have been insufficient. In a sequential, single-blind study, LeIGH et al. [128] recruited patients with again, quite typical COPD, although bronchodilator response was not an exclusion criteria and $38 \%$ of patients had sputum eosinophilia. They found that the presence of sputum eosinophilia predicted response to ICS and ICS use was associated with a reduction in sputum eosinophils, although the reduction was significantly less marked than that observed with oral corticosteroids. In an RCT, a management algorithm for patients with COPD based on suppressing sputum eosinophilia to $\leqslant 3 \%$ was compared to usual specialist care. This strategy was able to reduce severe exacerbations requiring hospitalisation with, on average, no more ICS or oral corticosteroid 
TABLE 2 Indicators of a probable response to inhaled corticosteroids in patients with chronic obstructive pulmonary disease

History of childhood asthma or atopy

Onset of respiratory disease prior to the age of 40 years

Cumulative smoking history $<20$ pack-years

FEV 1 bronchodilator response $\geqslant 12 \%$ and $\geqslant 400 \mathrm{~mL}$

Normal diffusing capacity

Peripheral blood eosinophilia

Sputum eosinophilia

Not $F E V_{1}<50 \%$ predicted

Not history of frequent exacerbations

FEV1: forced expiratory volume in $1 \mathrm{~s}$.

use than those in the usual-care group [129]. Surprisingly, in GLUCOLD (Groningen and Leiden Universities Study of Corticosteroids in Obstructive Lung Disease), the use of high-dose fluticasone in patients with COPD, over a 2.5-year period, was associated with an increase in sputum eosinophils [130]. Sputum inflammometry [131] has not been widely adopted, at least in part due to the technical expertise required [132]; however, it has been used successfully in routine specialist care by some [133]. While broader prospective studies including cost-benefit analyses would be helpful [134], sputum inflammometry currently appears to provide the single best measure to predict response to ICS among patients with significant airway disease [133]. It also provides information on the bacterial nature of exacerbations [135].

Other potential markers of response to ICS are needed. Peripheral blood eosinophils were found to predict eosinophilic exacerbations of COPD [135] and oral corticosteroid responsiveness of AECOPD [136]. Expired nitric oxide is of limited usefulness in COPD because it is affected by smoking and values fall with increasing airflow limitation $[137,138]$. However, there may be some utility for expired nitric oxide in ACOS [139]. Airway hyperresponsiveness to methacholine or histamine may be a marker of phenotypic variability in COPD [140] but its measurement is confounded by the degree of airflow limitation at baseline and current smoking [141, 142]. Furthermore, it is not recommended in patients with severe airflow limitation [143].

A promising approach is to combine potential indicators of response to ICS into a predictive algorithm [144]. Cluster analysis has been applied to patients with signs of airway disease in the general population, providing phenotypes that may be more or less likely to respond to ICS [145]. This approach has been used in patients with a clinical diagnosis of COPD to define differences in comorbidity and prognosis, but potential markers of response to ICS were not included in the analysis [146]. An overlap syndrome of patients with severe COPD and markers of asthma has been identified using cluster analysis by some [145] but not others [147]. Simple allocation rules need to be developed and tested to provide a clinically useful tool [148] that can be applied to patients where the decision to treat or not with ICS is most pertinent; that is, patients with significant airway obstruction and a relevant smoking history ( $\geqslant 20$ pack-years).

FIGURE 2 Improvement in postbronchodilator forced expiratory volume in $1 \mathrm{~s}$ (FEV 1 ) in patients with chronic obstructive pulmonary disease according to tertiles ( $\mathrm{T}$ ) of increasing sputum eosinophilia. *: $\mathrm{p}<0.05$. Reproduced from [127] with permission from the publisher.

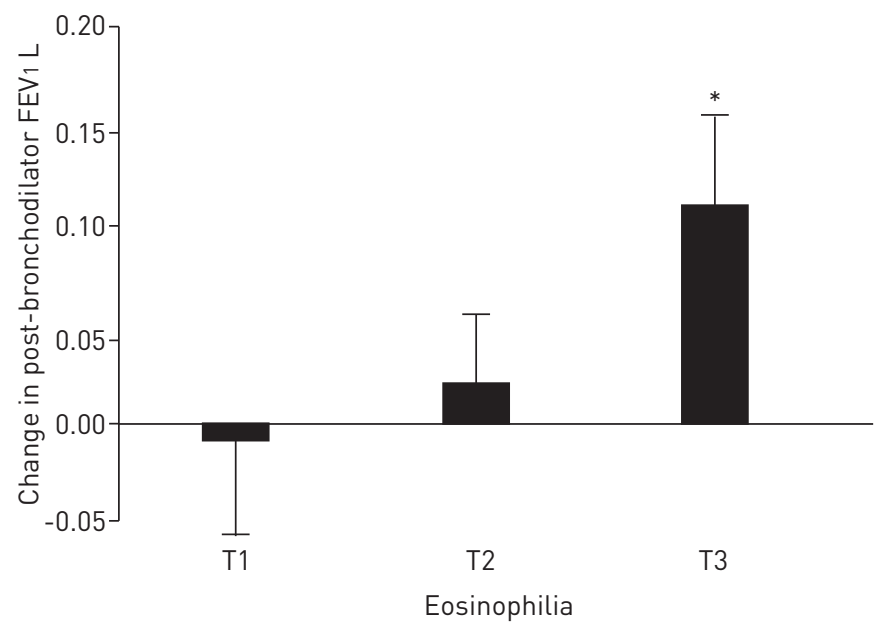


FIGURE 3 Occurrence of moderate and severe exacerbations of chronic obstructive pulmonary disease in subjects in whom inhaled corticosteroids (ICS) were gradually withdrawn compared with subjects in whom it was continued. Reproduced from [151] with permission from the publisher.

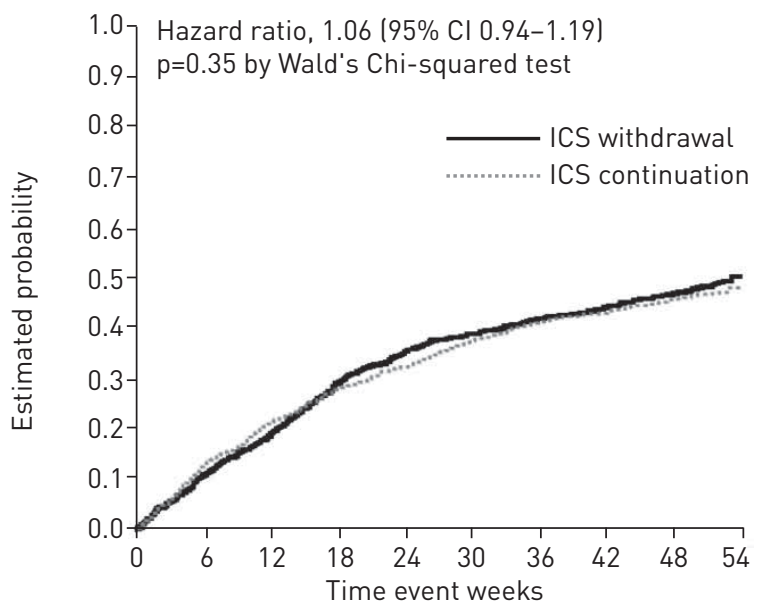

At risk $n$

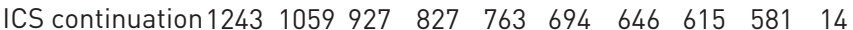
ICS withdrawal $12421090965 \quad 825 \quad 740 \quad 688 \quad 646 \quad 607 \quad 570 \quad 19$

\section{Conclusion}

The evidence of benefit of ICS and, therefore, of the LABA/ICS combinations in COPD is limited by methodological problems. One must conclude that there is no survival benefit independent of the effect of long-acting bronchodilation and no effect on FEV1 decline, and that the possible benefit on reducing exacerbations is probably overestimated and, for severe exacerbations, not greater than that obtained with long-acting bronchodilators. However, there is substantial evidence for adverse effects from the use of ICS in patients with COPD, most notably severe pneumonia resulting in excess deaths. It therefore appears important to limit use of ICS to the minority of patients with COPD who might benefit. Currently, the most reliable predictor of response to ICS in COPD is the presence of eosinophilic inflammation in the sputum. There is an urgent need for more and better markers of benefit and risk that can be tested in randomised trials for use in routine specialist practice. It is time to start devising randomised trials for the future with methods that can incorporate these markers to optimise the treatment of highly heterogeneous COPD patients. Currently, given the overall safety and effectiveness of long-acting bronchodilators $[149$, 150] in subjects without an asthma component to their COPD, we believe use of such agents without an associated ICS should be favoured at all levels of COPD severity. A recent study of the gradual withdrawal of ICS in stable but severe patients with COPD was reassuring as to the safety of such an approach, finding no excess in moderate or severe exacerbations when compared to patients maintained on ICS [151] (fig. 3).

\section{References}

1 Lozano R, Naghavi M, Foreman K, et al. Global and regional mortality from 235 causes of death for 20 age groups in 1990 and 2010: a systematic analysis for the Global Burden of Disease Study 2010. Lancet 2012; 380: 2095-2128.

2 Chapman KR, Mannino DM, Soriano JB, et al. Epidemiology and costs of chronic obstructive pulmonary disease. Eur Respir J 2006; 27: 188-207.

3 Gershon AS, Wang C, Wilton AS, et al. Trends in chronic obstructive pulmonary disease prevalence, incidence, and mortality in Ontario, Canada, 1996 to 2007: a population-based study. Arch Intern Med 2010; 170: 560-565.

4 Gershon AS, Guan J, Victor JC, et al. Quantifying health services use for chronic obstructive pulmonary disease. Am J Respir Crit Care Med 2013; 187: 596-601.

5 Mannino DM, Buist AS. Global burden of COPD: risk factors, prevalence, and future trends. Lancet 2007; 370: 765-773.

6 Sin DD, Tu JV. Inhaled corticosteroids and the risk of mortality and readmission in elderly patients with chronic obstructive pulmonary disease. Am J Respir Crit Care Med 2001; 164: 580-584.

7 Soriano JB, Vestbo J, Pride NB, et al. Survival in COPD patients after regular use of fluticasone propionate and salmeterol in general practice. Eur Respir J 2002; 20: 819-825.

8 Mapel DW, Hurley JS, Roblin D, et al. Survival of COPD patients using inhaled corticosteroids and long-acting beta agonists. Respir Med 2006; 100: 595-609.

9 Kiri VA, Pride NB, Soriano JB, et al. Inhaled corticosteroids in chronic obstructive pulmonary disease: results from two observational designs free of immortal time bias. Am J Respir Crit Care Med 2005; 172: 460-464.

10 Suissa S. Effectiveness of inhaled corticosteroids in chronic obstructive pulmonary disease: immortal time bias in observational studies. Am J Respir Crit Care Med 2003; 168: 49-53.

11 Suissa S. Immeasurable time bias in observational studies of drug effects on mortality. Am J Epidemiol 2008; 168 329-335.

12 Pauwels RA, Lofdahl CG, Laitinen LA, et al. Long-term treatment with inhaled budesonide in persons with mild chronic obstructive pulmonary disease who continue smoking. European Respiratory Society Study on Chronic Obstructive Pulmonary Disease. N Engl J Med 1999; 340: 1948-1953. 
13 Vestbo J, Sorensen T, Lange $\mathrm{P}$, et al. Long-term effect of inhaled budesonide in mild and moderate chronic obstructive pulmonary disease: a randomised controlled trial. Lancet 1999; 353: 1819-1823.

14 Lung Health Study Research Group. Effect of inhaled triamcinolone on the decline in pulmonary function in chronic obstructive pulmonary disease. N Engl J Med 2000; 343: 1902-1909.

15 Burge PS, Calverley PM, Jones PW, et al. Randomised, double blind, placebo controlled study of fluticasone propionate in patients with moderate to severe chronic obstructive pulmonary disease: the ISOLDE trial. BMJ 2000; 320: 1297-1303.

16 Calverley PM, Boonsawat W, Cseke Z, et al. Maintenance therapy with budesonide and formoterol in chronic obstructive pulmonary disease. Eur Respir J 2003; 22: 912-919.

17 Calverley P, Pauwels R, Vestbo J, et al. Combined salmeterol and fluticasone in the treatment of chronic obstructive pulmonary disease: a randomised controlled trial. Lancet 2003; 361: 449-456.

18 Szafranski W, Cukier A, Ramirez A, et al. Efficacy and safety of budesonide/formoterol in the management of chronic obstructive pulmonary disease. Eur Respir J 2003; 21: 74-81.

19 Alsaeedi A, Sin DD, McAlister FA. The effects of inhaled corticosteroids in chronic obstructive pulmonary disease: a systematic review of randomized placebo-controlled trials. Am J Med 2002; 113: 59-65.

20 Aaron SD, Fergusson D, Marks GB, et al. Counting, analysing and reporting exacerbations of COPD in randomised controlled trials. Thorax 2008; 63: 122-128.

21 Suissa S. Statistical treatment of exacerbations in therapeutic trials of chronic obstructive pulmonary disease. Am J Respir Crit Care Med 2006; 173: 842-846.

22 Hurst JR, Vestbo J, Anzueto A, et al. Susceptibility to exacerbation in chronic obstructive pulmonary disease. N Engl J Med 2010; 363: 1128-1138.

23 Kardos $\mathrm{P}$, Wencker M, Glaab $\mathrm{T}$, et al. Impact of salmeterol/fluticasone propionate versus salmeterol on exacerbations in severe chronic obstructive pulmonary disease. Am J Respir Crit Care Med 2007; 175: 144-149.

24 Dransfield MT, Bourbeau J, Jones PW, et al. Once-daily inhaled fluticasone furoate and vilanterol versus vilanterol only for prevention of exacerbations of COPD: two replicate double-blind, parallel-group, randomised controlled trials. Lancet Respir Med 2013; 1: 210-223.

Calverley PM, Anderson JA, Celli B, et al. Salmeterol and fluticasone propionate and survival in chronic obstructive pulmonary disease. N Engl J Med 2007; 356: 775-789.

26 Ferguson GT, Anzueto A, Fei R, et al. Effect of fluticasone propionate/salmeterol (250/50 microg) or salmeterol $(50 \mu \mathrm{g})$ on COPD exacerbations. Respir Med 2008; 102: 1099-1108.

27 Keene ON, Calverley PM, Jones PW, et al. Statistical analysis of exacerbation rates in COPD: TRISTAN and ISOLDE revisited. Eur Respir J 2008; 32: 17-24.

28 Yang IA, Clarke MS, Sim EH, et al. Inhaled corticosteroids for stable chronic obstructive pulmonary disease. Cochrane Database Syst Rev 2012; CD002991.

29 Spencer S, Karner C, Cates CJ, et al. Inhaled corticosteroids versus long-acting $\beta_{2}$-agonists for chronic obstructive pulmonary disease. Cochrane Database Syst Rev 2011; CD007033.

30 La Vecchia C, Fabbri LM. Prevention of death in COPD. N Engl J Med 2007; 356: 2211-2212.

31 Kesten S, Plautz M, Piquette CA, et al. Premature discontinuation of patients: a potential bias in COPD clinical trials. Eur Respir J 2007; 30: 898-906.

32 Vestbo J, Anderson JA, Calverley PM, et al. Bias due to withdrawal in long-term randomised trials in COPD: evidence from the TORCH study. Clin Respir J 2011; 5: 44-49.

33 Aaron SD, Vandemheen KL, Fergusson D, et al. Tiotropium in combination with placebo, salmeterol, or fluticasone-salmeterol for treatment of chronic obstructive pulmonary disease: a randomized trial. Ann Int Med 2007; 146: 545-555.

34 Suissa S, Ernst P, Vandemheen KL, et al. Methodological issues in therapeutic trials of COPD. Eur Respir J 2008; 31: 927-933.

35 Keene ON, Vestbo J, Anderson JA, et al. Methods for therapeutic trials in COPD: lessons from the TORCH trial. Eur Respir J 2009; 34: 1018-1023.

36 Huiart L, Ernst P, Suissa S. Cardiovascular morbidity and mortality in COPD. Chest 2005; 128: 2640-2646.

37 Antonelli Incalzi R, Fuso L, De Rosa M, et al. Co-morbidity contributes to predict mortality of patients with chronic obstructive pulmonary disease. Eur Respir J 1997; 10: 2794-2800.

38 Curkendall SM, DeLuise C, Jones JK, et al. Cardiovascular disease in patients with chronic obstructive pulmonary disease, Saskatchewan Canada cardiovascular disease in COPD patients. Ann Epidemiol 2006; 16: 63-70.

39 Huiart L, Ernst P, Ranouil X, et al. Low-dose inhaled corticosteroids and the risk of acute myocardial infarction in COPD. Eur Respir J 2005; 25: 634-639.

40 Suissa S, Brassard P, Ernst P. Inhaled corticosteroid use in asthma and the prevention of myocardial infarction. Am J Med 2003; 115: 377-381.

41 Calverley PM, Anderson JA, Celli B, et al. Cardiovascular events in patients with COPD: TORCH study results. Thorax 2010; 65: 719-725.

42 Vestbo J, Anderson J, Brook RD, et al. The study to understand mortality and morbidity in COPD (SUMMIT) study protocol. Eur Respir J 2013; 41: 1017-1022.

43 Suissa S. Will SUMMIT reach the peak in COPD? Thorax 2014; 69: 405-407.

44 Nannini LJ, Lasserson TJ, Poole P. Combined corticosteroid and long-acting $\beta_{2}$-agonist in one inhaler versus long-acting $\beta_{2}$-agonists for chronic obstructive pulmonary disease. Cochrane Database Syst Rev 2012; CD006829.

45 Bousquet J. Inhaled corticosteroids in severe COPD. Lancet Respir Med 2013; 1: 177-178.

46 Halpin DM. Evaluating the effectiveness of combination therapy to prevent COPD exacerbations: the value of NNT analysis. Int J Clin Pract 2005; 59: 1187-1194.

47 Aaron SD, Fergusson DA. Exaggeration of treatment benefits using the "event-based" number needed to treat. CMAJ 2008; 179: 669-671.

48 Anzueto A, Ferguson GT, Feldman G, et al. Effect of fluticasone propionate/salmeterol (250/50) on COPD exacerbations and impact on patient outcomes. COPD 2009; 6: 320-329.

49 Suissa S. Number needed to treat in COPD: exacerbations versus pneumonias. Thorax 2013; 68: 540-543.

50 Fletcher C, Peto R. The natural history of chronic airflow obstruction. Br Med J 1977; 1: 1645-1648. 
51 Highland $\mathrm{KB}$, Strange C, Heffner JE. Long-term effects of inhaled corticosteroids on FEV1 in patients with chronic obstructive pulmonary disease. A meta-analysis. Ann Int Med 2003; 138: 969-973.

52 Sutherland ER, Allmers H, Ayas NT, et al. Inhaled corticosteroids reduce the progression of airflow limitation in chronic obstructive pulmonary disease: a meta-analysis. Thorax 2003; 58: 937-941.

53 Celli BR, Thomas NE, Anderson JA, et al. Effect of pharmacotherapy on rate of decline of lung function in chronic obstructive pulmonary disease: results from the TORCH study. Am J Respir Crit Care Med 2008; 178: 332-338.

54 Suissa S. Lung function decline in COPD trials: bias from regression to the mean. Eur Respir J 2008; 32: 829-831.

55 Almirall J, Bolibar I, Serra-Prat M, et al. New evidence of risk factors for community-acquired pneumonia: a population-based study. Eur Respir J 2008; 31: 1274-1284.

56 Restrepo MI, Mortensen EM, Pugh JA, et al. COPD is associated with increased mortality in patients with community-acquired pneumonia. Eur Respir J 2006; 28: 346-351.

57 Crim C, Calverley PM, Anderson JA, et al. Pneumonia risk in COPD patients receiving inhaled corticosteroids alone or in combination: TORCH study results. Eur Respir J 2009; 34: 641-647.

58 Ernst $\mathrm{P}$, Gonzalez AV, Brassard P, et al. Inhaled corticosteroid use in chronic obstructive pulmonary disease and the risk of hospitalization for pneumonia. Am J Respir Crit Care Med 2007; 176: 162-166.

59 Wedzicha JA, Calverley PM, Seemungal TA, et al. The prevention of COPD exacerbations by salmeterol/ fluticasone propionate or tiotropium bromide. Am J Respir Crit Care Med 2008; 177: 19-26.

60 Drummond MB, Dasenbrook EC, Pitz MW, et al. Inhaled corticosteroids in patients with stable chronic obstructive pulmonary disease: a systematic review and meta-analysis. JAMA 2008; 300: 2407-2416.

61 Singh S, Amin AV, Loke YK. Long-term use of inhaled corticosteroids and the risk of pneumonia in chronic obstructive pulmonary disease: a meta-analysis. Arch Intern Med 2009; 169: 219-229.

62 Calverley PM, Stockley RA, Seemungal TA, et al. Reported pneumonia in patients with COPD: findings from the INSPIRE study. Chest 2011; 139: 505-512.

63 Gershon AS, Campitelli MA, Croxford R, et al. Combination long-acting $\beta$-agonists and inhaled corticosteroids compared with long-acting $\beta$-agonists alone in older adults with chronic obstructive pulmonary disease. JAMA 2014; 312: 1114-1121.

64 Sin DD, Tashkin D, Zhang X, et al. Budesonide and the risk of pneumonia: a meta-analysis of individual patient data. Lancet 2009; 374: 712-719.

65 Suissa S, Patenaude V, Lapi F, et al. Inhaled corticosteroids in COPD and the risk of serious pneumonia. Thorax 2013; 68: 1029-1036.

66 Janson C, Larsson K, Lisspers KH, et al. Pneumonia and pneumonia related mortality in patients with COPD treated with fixed combinations of inhaled corticosteroid and long acting $\beta_{2}$ agonist: observational matched cohort study (PATHOS). BMJ 2013; 346: f3306.

67 O’Byrne PM, Pedersen S, Carlsson LG, et al. Risks of pneumonia in asthmatic patients taking inhaled corticosteroids. Am J Respir Crit Care Med 2011; 183: 589-595.

68 Kew KM, Seniukovich A. Inhaled steroids and risk of pneumonia for chronic obstructive pulmonary disease. Cochrane Database Syst Rev 2014; CD010115.

69 Malo de Molina R, Mortensen EM, Restrepo MI, et al. Inhaled corticosteroid use is associated with lower mortality for subjects with COPD and hospitalised with pneumonia. Eur Respir J 2010; 36: 751-757.

70 Singanayagam A, Chalmers JD, Akram AR, et al. Impact of inhaled corticosteroid use on outcome in COPD patients admitted with pneumonia. Eur Respir J 2011; 38: 36-41.

71 Restrepo MI, Mortensen EM, Anzueto A. Are COPD patients with pneumonia who are taking inhaled corticosteroids at higher risk of dying? Eur Respir J 2011; 38: 1-3.

72 Brassard P, Suissa S, Kezouh A, et al. Inhaled corticosteroids and risk of tuberculosis in patients with respiratory diseases. Am J Respir Crit Care Med 2011; 183: 675-678.

73 Lee $\mathrm{CH}$, Kim K, Hyun MK, et al. Use of inhaled corticosteroids and the risk of tuberculosis. Thorax 2013; 68: $1105-1113$.

74 Andréjak C, Nielsen R, Thomsen VØ, et al. Chronic respiratory disease, inhaled corticosteroids and risk of non-tuberculous mycobacteriosis. Thorax 2013; 68: 256-262.

75 Ernst P, Dell'Aniello S, Mikaeloff Y, et al. Risk of herpes zoster in patients prescribed inhaled corticosteroids: a cohort study. BMC Pulm Med 2011; 11: 59.

76 Buehring B, Viswanathan R, Binkley N, et al. Glucocorticoid-induced osteoporosis: an update on effects and management. J Allergy Clin Immunol 2013; 132: 1019-1030.

77 Sin DD, Man JP, Man SF. The risk of osteoporosis in Caucasian men and women with obstructive airways disease. Am J Med 2003; 114: 10-14.

78 Hubbard RB, Smith CJ, Smeeth L, et al. Inhaled corticosteroids and hip fracture: a population-based case-control study. Am J Respir Crit Care Med 2002; 166: 1563-1566.

79 Weatherall M, James K, Clay J, et al. Dose-response relationship for risk of non-vertebral fracture with inhaled corticosteroids. Clin Exp Allergy 2008; 38: 1451-1458.

80 Suissa S, Baltzan M, Kremer R, et al. Inhaled and nasal corticosteroid use and the risk of fracture. Am J Respir Crit Care Med 2004; 169: 83-88.

81 Loke YK, Cavallazzi R, Singh S. Risk of fractures with inhaled corticosteroids in COPD: systematic review and meta-analysis of randomised controlled trials and observational studies. Thorax 2011; 66: 699-708

82 Dendukuri N, Blais L, LeLorier J. Inhaled corticosteroids and the risk of diabetes among the elderly. $\mathrm{Br} \mathrm{J} C$ lin Pharmacol 2002; 54: 59-64.

83 Blackburn D, Hux J, Mamdani M. Quantification of the risk of corticosteroid-induced diabetes mellitus among the elderly. J Gen Intern Med 2002; 17: 717-720.

84 O'Byrne PM, Rennard S, Gerstein H, et al. Risk of new onset diabetes mellitus in patients with asthma or COPD taking inhaled corticosteroids. Respir Med 2012; 106: 1487-1493.

85 Slatore CG, Bryson CL, Au DH. The association of inhaled corticosteroid use with serum glucose concentration in a large cohort. Am J Med 2009; 122: 472-478

86 Faul JL, Wilson SR, Chu JW, et al. The effect of an inhaled corticosteroid on glucose control in type 2 diabetes. Clin Med Res 2009; 7: 14-20. 
Suissa S, Kezouh A, Ernst P. Inhaled corticosteroids and the risks of diabetes onset and progression. Am J Med 2010; 123: 1001-1006.

Zimmerman B, Gold M, Wherrett D, et al. Adrenal suppression in two patients with asthma treated with low doses of the inhaled steroid fluticasone propionate. J Allergy Clin Immunol 1998; 101: 425-426.

Todd GRC, Acerini CL, Ross-Russell R, et al. Survey of adrenal crisis associated with inhaled corticosteroids in the United Kingdom. Arch Dis Child 2002; 87: 457-461.

Drake AJ, Howells RJ, Shield JP, et al. Symptomatic adrenal insufficiency presenting with hypoglycaemia in children with asthma receiving high dose inhaled fluticasone propionate. BMJ 2002; 324: 1081-1082.

Samaras K, Pett S, Gowers A, et al. Iatrogenic Cushing's syndrome with osteoporosis and secondary adrenal failure in human immunodeficiency virus-infected patients receiving inhaled corticosteroids and ritonavirboosted protease inhibitors: six cases. J Clin Endocrinol Metab 2005; 90: 4394-4398.

Li AM. Ritonavir and fluticasone: beware of this potentially fatal combination. J Pediatr 2006; 148: $294-295$.

Clark DJ, Grove A, Cargill RI, et al. Comparative adrenal suppression with inhaled budesonide and fluticasone propionate in adult asthmatic patients. Thorax 1996; 51: 262-266.

Mortimer KJ, Tata LJ, Smith CJ, et al. Oral and inhaled corticosteroids and adrenal insufficiency: a case-control study. Thorax 2006; 61: 405-408.

Lapi F, Kezouh A, Suissa S, et al. The use of inhaled corticosteroids and the risk of adrenal insufficiency. Eur Respir J 2013; 42: 79-86.

Derom E, Van De Velde V, Marissens S, et al. Effects of inhaled ciclesonide and fluticasone propionate on cortisol secretion and airway responsiveness to adenosine 5'monophosphate in asthmatic patients. Pulm Pharmacol Ther 2005; 18: 328-336.

Fardon TC, Lee DK, Haggart K, et al. Adrenal suppression with dry powder formulations of fluticasone propionate and mometasone furoate. Am J Respir Crit Care Med 2004; 170: 960-966.

Cumming RG, Mitchell P, Leeder SR. Use of inhaled corticosteroids and the risk of cataracts. N Engl J Med 1997; 337: 8-14

Garbe E, Suissa S, LeLorier J. Association of inhaled corticosteroid use with cataract extraction in elderly patients. JAMA 1998; 280: 539-543.

Jick SS, Vasilakis-Scaramozza C, Maier WC. The risk of cataract among users of inhaled steroids. Epidemiology 2001; 12: 229-234.

Ernst P, Baltzan M, Deschenes J, et al. Low-dose inhaled and nasal corticosteroid use and the risk of cataracts. Eur Respir J 2006; 27: 1168-1174.

Garbe E, LeLorier J, Boivin JF, et al. Risk of ocular hypertension or open-angle glaucoma in elderly patients on oral glucocorticoids. Lancet 1997; 350: 979-982.

Garbe E, LeLorier J, Boivin JF, Suissa S. Inhaled and nasal glucocorticoids and the risks of ocular hypertension or open-angle glaucoma. JAMA 1997; 277: 722-727.

Gonzalez AV, Li G, Suissa S, et al. Risk of glaucoma in elderly patients treated with inhaled corticosteroids for chronic airflow obstruction. Pulm Pharmacol Ther 2010; 23: 65-70.

Vestbo J, Hurd SS, Agusti AG, et al. Global strategy for the diagnosis, management, and prevention of chronic obstructive pulmonary disease: GOLD executive summary. Am J Respir Crit Care Med 2013; 187: 347-365.

O’Donnell DE, Aaron S, Bourbeau J, et al. Canadian Thoracic Society recommendations for management of chronic obstructive pulmonary disease - 2007 update. Can Respir J 2007; 14: Suppl. B, 5B-32B.

Tashkin DP, Altose MD, Connett JE, et al. Methacholine reactivity predicts changes in lung function over time in smokers with early chronic obstructive pulmonary disease. The Lung Health Study Research Group. Am J Respir Crit Care Med 1996; 153: 1802-1811.

Celli BR, Halbert RJ, Nordyke RJ, et al. Airway obstruction in never smokers: results from the Third National Health and Nutrition Examination Survey. Am J Med 2005; 118: 1364-1372.

Mannino DM, Gagnon RC, Petty TL, et al. Obstructive lung disease and low lung function in adults in the United States: data from the National Health and Nutrition Examination Survey, 1988-1994. Arch Intern Med 2000; 160: 1683-1689.

Menezes AM, Perez-Padilla R, Jardim JR, et al. Chronic obstructive pulmonary disease in five Latin American cities (the PLATINO study): a prevalence study. Lancet 2005; 366: 1875-1881.

Tai A, Tran H, Roberts M, et al. The association between childhood asthma and adult chronic obstructive pulmonary disease. Thorax 2014; 69: 805-810.

Buist AS, McBurnie MA, Vollmer WM, et al. International variation in the prevalence of COPD (the BOLD Study): a population-based prevalence study. Lancet 2007; 370: 741-750.

Postma DS, Brusselle G, Bush A, et al. I have taken my umbrella, so of course it does not rain. Thorax 2012; 67: 88-89.

Pavord ID, Wardlaw AJ. The A to E of airway disease. Clin Exp Allergy 2010; 40: 62-67.

Global Initiative for Asthma. Global Strategy for Asthma Management and Prevention. www.ginasthma.org/local/ uploads/files/GINA_Report_2014_Aug12.pdf Date last updated: August 12, 2014.

Miravitlles M, Soler-Cataluna JJ, Calle M, et al. Treatment of COPD by clinical phenotypes: putting old evidence into clinical practice. Eur Respir J 2013; 41: 1252-1256.

Suissa S, Dell'Aniello S, Ernst P. Long-term natural history of chronic obstructive pulmonary disease: severe exacerbations and mortality. Thorax 2012; 67: 957-963.

Albert P, Agusti A, Edwards L, et al. Bronchodilator responsiveness as a phenotypic characteristic of established chronic obstructive pulmonary disease. Thorax 2012; 67: 701-708.

9 Calverley PM, Burge PS, Spencer S, et al. Bronchodilator reversibility testing in chronic obstructive pulmonary disease. Thorax 2003; 58: 659-664.

0 Tan WC, Bourbeau J, Hernandez P, et al. Bronchodilator responsiveness and reported respiratory symptoms in an adult population. PLoS One 2013; 8: e58932.

Fabbri LM, Romagnoli M, Corbetta L, et al. Differences in airway inflammation in patients with fixed airflow obstruction due to asthma or chronic obstructive pulmonary disease. Am J Respir Crit Care Med 2003; 167: 418-424. Green RH, Brightling CE, Woltmann G, et al. Analysis of induced sputum in adults with asthma: identification of subgroup with isolated sputum neutrophilia and poor response to inhaled corticosteroids. Thorax 2002; 57: 875-879. 
123 McGrath KW, Icitovic N, Boushey HA, et al. A large subgroup of mild-to-moderate asthma is persistently noneosinophilic. Am J Respir Crit Care Med 2012; 185: 612-619.

124 Saha S, Brightling CE. Eosinophilic airway inflammation in COPD. Int J Chron Obstruct Pulmon Dis 2006; 1: 39-47.

125 Brightling CE, Monteiro W, Ward R, et al. Sputum eosinophilia and short-term response to prednisolone in chronic obstructive pulmonary disease: a randomised controlled trial. Lancet 2000; 356: 1480-1485.

126 Pizzichini E, Pizzichini MM, Gibson P, et al. Sputum eosinophilia predicts benefit from prednisone in smokers with chronic obstructive bronchitis. Am J Respir Crit Care Med 1998; 158: 1511-1517.

127 Brightling CE, McKenna S, Hargadon B, et al. Sputum eosinophilia and the short term response to inhaled mometasone in chronic obstructive pulmonary disease. Thorax 2005; 60: 193-198.

128 Leigh R, Pizzichini MM, Morris MM, et al. Stable COPD: predicting benefit from high-dose inhaled corticosteroid treatment. Eur Respir J 2006; 27: 964-971.

129 Siva R, Green RH, Brightling CE, et al. Eosinophilic airway inflammation and exacerbations of COPD: a randomised controlled trial. Eur Respir J 2007; 29: 906-913.

130 Lapperre TS, Snoeck-Stroband JB, Gosman MM, et al. Effect of fluticasone with and without salmeterol on pulmonary outcomes in chronic obstructive pulmonary disease: a randomized trial. Ann Intern Med 2009; 151: 517-527.

131 Pavord ID, Gibson PG. Inflammometry: the current state of play. Thorax 2012; 67: 191-192.

132 Petsky HL, Cates CJ, Lasserson TJ, et al. A systematic review and meta-analysis: tailoring asthma treatment on eosinophilic markers (exhaled nitric oxide or sputum eosinophils). Thorax 2012; 67: 199-208.

133 Nair P. Update on clinical inflammometry for the management of airway diseases. Can Respir J 2013; 20: $117-120$

134 Maestrelli P. Same role and same treatment for airway eosinophilia in asthma and COPD? Eur Respir J 2007; 29: 831-833.

135 Bafadhel M, McKenna S, Terry S, et al. Acute exacerbations of chronic obstructive pulmonary disease: identification of biologic clusters and their biomarkers. Am J Respir Crit Care Med 2011; 184: 662-671.

136 Bafadhel M, Davies L, Calverley PM, et al. Blood eosinophil guided prednisolone therapy for exacerbations of COPD: a further analysis. Eur Respir J 2014; 44: 789-791.

137 Malinovschi A, Janson C, Holmkvist T, et al. Effect of smoking on exhaled nitric oxide and flow-independent nitric oxide exchange parameters. Eur Respir J 2006; 28: 339-345.

138 Corradi M, Majori M, Cacciani GC, et al. Increased exhaled nitric oxide in patients with stable chronic obstructive pulmonary disease. Thorax 1999; 54: 572-575.

139 Dweik RA, Boggs PB, Erzurum SC, et al. An official ATS clinical practice guideline: interpretation of exhaled nitric oxide levels (Feno) for clinical applications. Am J Respir Crit Care Med 2011; 184: 602-615.

140 van den Berge M, Vonk JM, Gosman M, et al. Clinical and inflammatory determinants of bronchial hyperresponsiveness in COPD. Eur Respir J 2012; 40: 1098-1105.

141 Juusela M, Pallasaho P, Ronmark E, et al. Dose-dependent association of smoking and bronchial hyperresponsiveness. Eur Respir J 2013; 42: 1503-1512.

142 James MT, Quan H, Tonelli M, et al. CKD and risk of hospitalization and death with pneumonia. Am J Kidney Dis 2009; 54: 24-32.

143 Sterk PJ, Fabbri LM, Quanjer PH, et al. Airway responsiveness. Standardized challenge testing with pharmacological, physical and sensitizing stimuli in adults. Eur Respir J 1993; 6: Suppl. 16, 53-83.

144 Yap E, Chua WM, Jayaram L, et al. Can we predict sputum eosinophilia from clinical assessment in patients referred to an adult asthma clinic? Int Med J 2013; 43: 46-52.

145 Weatherall M, Travers J, Shirtcliffe PM, et al. Distinct clinical phenotypes of airways disease defined by cluster analysis. Eur Respir J 2009; 34: 812-818.

146 Burgel PR, Paillasseur JL, Caillaud D, et al. Clinical COPD phenotypes: a novel approach using principal component and cluster analyses. Eur Respir J 2010; 36: 531-539.

147 Garcia-Aymerich J, Gomez FP, Benet M, et al. Identification and prospective validation of clinically relevant chronic obstructive pulmonary disease (COPD) subtypes. Thorax 2011; 66: 430-437.

148 Travers J, Weatherall M, Fingleton J, et al. Towards individualised medicine for airways disease: identifying clinical phenotype groups. Eur Respir J 2012; 39: 1033-1034.

149 Wedzicha JA, Decramer M, Ficker JH, et al. Analysis of chronic obstructive pulmonary disease exacerbations with the dual bronchodilator QVA149 compared with glycopyrronium and tiotropium (SPARK): a randomised, double-blind, parallel-group study. Lancet Respir Med 2013; 1: 199-209.

150 Wise RA, Anzueto A, Cotton D, et al. Tiotropium respimat inhaler and the risk of death in COPD. N Engl J Med 2013; 369: 1491-1501.

151 Magnussen H, Disse B, Rodriguez-Roisin R, et al. Withdrawal of inhaled glucocorticoids and exacerbations of COPD. N Engl J Med 2014; 371: 1285-1294. 